University of Nebraska - Lincoln

DigitalCommons@University of Nebraska - Lincoln

Faculty Publications from Nebraska Center for Materials and Nanoscience, Nebraska Center Materials and Nanoscience

for (NCMN)

4-25-2006

\title{
Highly coercive rapidly solidified Sm-Co alloys
}

\author{
Shampa Aich \\ University of Nebraska - Lincoln, saich2@unl.edu \\ V.K. Ravindran \\ University of Nebraska - Lincoln \\ Jeffrey E. Shield \\ lowa State University, jshield@unl.edu
}

Follow this and additional works at: https://digitalcommons.unl.edu/cmrafacpub

Part of the Nanoscience and Nanotechnology Commons

Aich, Shampa; Ravindran, V.K.; and Shield, Jeffrey E., "Highly coercive rapidly solidified Sm-Co alloys" (2006). Faculty Publications from Nebraska Center for Materials and Nanoscience. 7.

https://digitalcommons.unl.edu/cmrafacpub/7

This Article is brought to you for free and open access by the Materials and Nanoscience, Nebraska Center for (NCMN) at DigitalCommons@University of Nebraska - Lincoln. It has been accepted for inclusion in Faculty Publications from Nebraska Center for Materials and Nanoscience by an authorized administrator of DigitalCommons@University of Nebraska - Lincoln. 


\title{
Highly coercive rapidly solidified Sm-Co alloys
}

\author{
S. Aich, ${ }^{\text {a) } V . ~ K . ~ R a v i n d r a n, ~ a n d ~ J . ~ E . ~ S h i e l d ~}$ \\ Department of Mechanical Engineering and Center for Materials Research and Analysis, N104, WSEC, \\ University of Nebraska, Lincoln, Nebraska 68588
}

(Presented on 31 October 2005; published online 25 April 2006)

\begin{abstract}
Highly coercive $\left(H_{c}\right.$ up to $37 \mathrm{kOe}$ at $\left.300 \mathrm{~K}\right)$, high remanent permanent magnets have been achieved by rapid solidification of binary Sm-Co alloys and Sm-Co alloys modified with $\mathrm{Nb}$ and $\mathrm{C}$. Rapidly solidified $\mathrm{SmCo}_{x}$ alloys with $x$ ranging from 5 to 11.5 formed predominantly a solid solution $\mathrm{TbCu}_{7}$-type $\mathrm{SmCo}_{7}$ phase, although hep Co was observed for $x>7.3$. A coercivity value of $10 \mathrm{kOe}$ was observed for $x<6.1$, even though the microstructural scale was on the order of $1 \mu \mathrm{m}$. The coercivity decreased significantly with the presence of the hcp Co phase, which formed initially as $\sim 80 \mathrm{~nm}$ grains and, at higher $x$, as primary dendrites. Additions of 3 at. $\% \mathrm{Nb}$ or 3 and 5 at. $\% \mathrm{C}$ profoundly affected the coercivity values. Transmission electron microscopy (TEM) investigations revealed the origin of the improved coercivity. The addition of $\mathrm{Nb}$ resulted in a significant reduction in microstructural scale. The $\mathrm{SmCo}_{7}$ grain size decreased systematically with $\mathrm{Nb}$ content, reaching 150-200 nm at 3 at. \% Nb. The addition of C also significantly enhanced the coercivity, which systematically increased with $\mathrm{C}$ content and reached $37 \mathrm{kOe}$ at 5 at. \% $\mathrm{C}$. The effect of $\mathrm{C}$, however, resulted in morphological changes as TEM revealed the formation of an intergranular phase that effectively isolated the hard magnetic $\mathrm{SmCo}_{7}$ grains from one another, reducing magnetic interactions. Excellent isotropic energy products of 6-8 MGOe were also achieved. (C) 2006 American Institute of Physics. [DOI: 10.1063/1.2173238]
\end{abstract}

\section{INTRODUCTION}

There is a great deal of interest in developing coercivity in Sm-Co-based permanent magnets through simpler processing. For example, rapid solidification effectively forms the $\mathrm{TbCu}_{7}$-type metastable structure from which precipitation-hardened magnets derive their microstructures upon appropriate heat treatment. ${ }^{1-4}$ Efforts to produce improved magnetic properties in as-solidified Sm-Co alloys would eliminate the need for additional processing. Very high coercivity $(\sim 40 \mathrm{kOe})$ was observed in melt-spun Sm-Co. ${ }^{5,6}$ These alloys, however, relied on significant amounts of alloying additions to produce the proper solidification behavior necessary to obtain the high coercivity. Efforts to produce high coercivities without alloying additions have produced only modest results. ${ }^{7}$ Here, we have investigated the role of $\mathrm{Sm} / \mathrm{Co}$ ratio on the magnetic properties and also reported significant improvements in coercivity with only minor alloying additions.

\section{EXPERIMENTAL PROCEDURES}

Three series of alloys have been examined in this study. The first series were simple binary Sm-Co alloys with varying $\mathrm{Sm} / \mathrm{Co}$ ratios; these had a nominal composition of $\mathrm{SmCo}_{x}$ with $x$ ranging from 5 to 11.5 . The other series examined a fixed $\mathrm{Sm} / \mathrm{Co}$ ratio with $\mathrm{Nb}$ or $\mathrm{C}$ additions, with nominal compositions of $\left(\mathrm{SmCo}_{7.3}\right)_{100-y} T_{y}$, where $T=\mathrm{Nb}$ or $\mathrm{C}$ and $y=3$ and 5. The alloys were made from high purity $(>99.95 \%)$ elemental constituents by arc melting in a high purity argon atmosphere. Before arc melting, 5\% extra Sm

\footnotetext{
a) Author to whom correspondence should be addressed; electronic mail: saich2@unlserve.unl.edu
}

was added to the sample to compensate for loss due to Sm vaporization during melting. The ingot was then rapidly solidified by melt spinning in high purity argon at a chamber pressure of $1 \mathrm{~atm}$ and a tangential wheel velocity of $40 \mathrm{~m} / \mathrm{s}$.

The magnetic measurements were made by superconducting quantum interference device (SQUID) magnetometry at $300 \mathrm{~K}$ utilizing a Quantum Design MPMS with a maximum field of $7 \mathrm{~T}$. Magnetic measurements were made on several ribbon pieces mounted so that the magnetic field was applied in the plane of the ribbon. Transmission electron microscopy was accomplished with a JEOL2010 operating at $200 \mathrm{kV}$. Electron transparency was achieved by mounting the melt-spun ribbon on a slightly polished $\mathrm{Cu}$ oval and by ion milling to perforation using a Gatan Duomill or precision ion polishing system (PIPS) at $4.5 \mathrm{kV}$. Structural characterization by $\mathrm{x}$-ray diffraction was also conducted using a Philips diffractometer and $\mathrm{Cu} K \alpha$ radiation.

\section{RESULTS AND DISCUSSIONS}

$\mathrm{X}$-ray diffraction and microscopic observation revealed that rapid solidification of the binary $\mathrm{SmCo}_{x}$ alloys with $x$
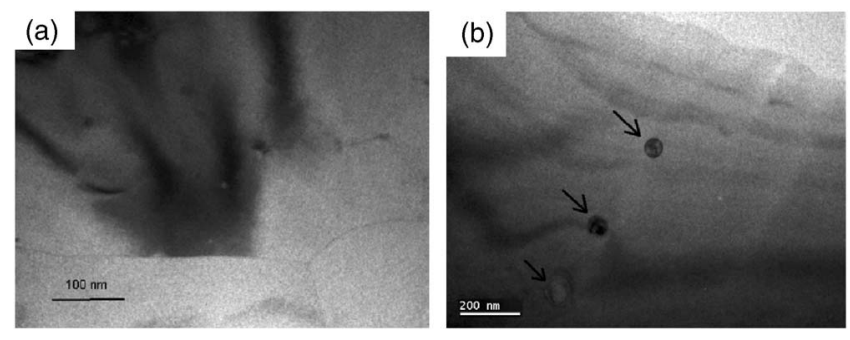

FIG. 1. Transmission electron micrographs revealing the microstructure of the $\mathrm{SmCo}_{x}$ alloy melt spun at $40 \mathrm{~m} / \mathrm{s}$ (a) for $x=6.1$, showing only large 1:7 grains, and (b) for $x=7.3$, showing large 1:7 grains and scattered Co precipitates. 

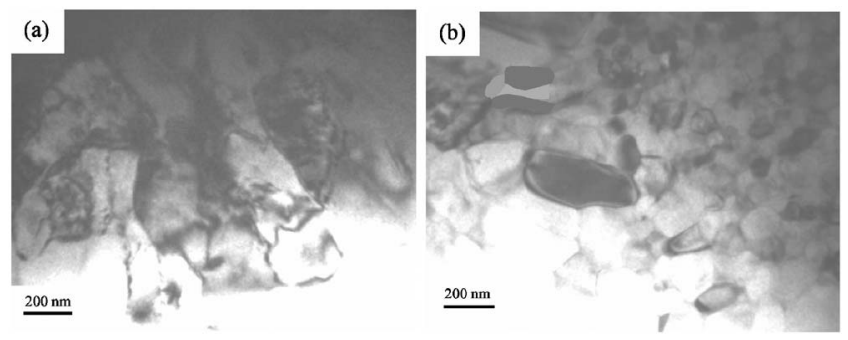

FIG. 2. Transmission electron micrographs revealing the microstructure of (a) the $\left(\mathrm{Sm}_{0.12} \mathrm{Co}_{0.88}\right)_{97} \mathrm{Nb}_{3}$ alloy melt spun at $40 \mathrm{~m} / \mathrm{s}$, showing equiaxed smaller 1:7 grains, and (b) the $\left(\mathrm{Sm}_{0.12} \mathrm{Co}_{0.88}\right)_{97} \mathrm{C}_{3}$ alloy melt spun at $40 \mathrm{~m} / \mathrm{s}$, showing a mixture of equiaxed grains having a wide range of size distribution.

ranging from 5 to 11.5 resulted in the formation of only the $\mathrm{SmCo}_{7}$ phase with the $\mathrm{TbCu}_{7}$-type structure for $x<7.3$, and for $x \geqslant 7.3$ a two-phase mixture of the $\mathrm{SmCo}_{7}$ phase and $\mathrm{Co}$ was observed. The rapid solidification effectively suppressed the formation of the equilibrium $\mathrm{Sm}_{2} \mathrm{Co}_{17}$ phase with the $\mathrm{Th}_{2} \mathrm{Zn}_{17}$-type structure. However, the rapid solidification resulted in only modest refinement of the microstructural scale. Figure 1 shows the transmission electron micrographs of the $\mathrm{SmCo}_{x}$ with $x=7.3$ and 6.1. The grain size of the $\mathrm{SmCo}_{7}$ phase was observed to be on the order of $1 \mu \mathrm{m}$ for all $\mathrm{SmCo}_{x}$ alloys with $x<11.5$, which is rather coarse considering the processing route. The other binary alloys formed a variety of microstructures. ${ }^{8}$ Also notable in the Fig. 1(b) is the presence of a second phase, which electron diffraction revealed to be fcc Co.

Alloying to form $\left(\mathrm{SmCo}_{7.3}\right)_{97} T_{3}$ with $T=\mathrm{C}$ and $\mathrm{Nb}$ eliminated the fcc Co formation, as neither x-ray diffraction nor microscopic examination revealed any fcc Co. However, both alloying additions resulted in a refinement in the grain size (Fig. 2). Both $\mathrm{Nb}$ and $\mathrm{C}$ additions of 3 at. \% reduced the grain size to $150-200 \mathrm{~nm}$. However, the $\mathrm{C}$ addition resulted in the formation of a second phase along the grain boundaries. No similar second phase was observed for the alloy with the $\mathrm{Nb}$ addition. An alloy with a higher level of $\mathrm{C}$ addition (5 at. \%) was examined as well. The higher concentration had a dramatic effect on the microstructure, producing a change in morphology from equiaxed grains to a dendritic structure which was surrounded by a large fraction of a second phase (Fig. 3). This second phase was determined to be $\mathrm{Sm}_{2} \mathrm{C}_{3}$ from $\mathrm{x}$-ray diffraction analysis.

The magnetic properties were strongly dependent on the microstructures. In the binary (unalloyed) $\mathrm{SmCo}_{x}$ alloys, the coercivity was significantly affected not so much on the
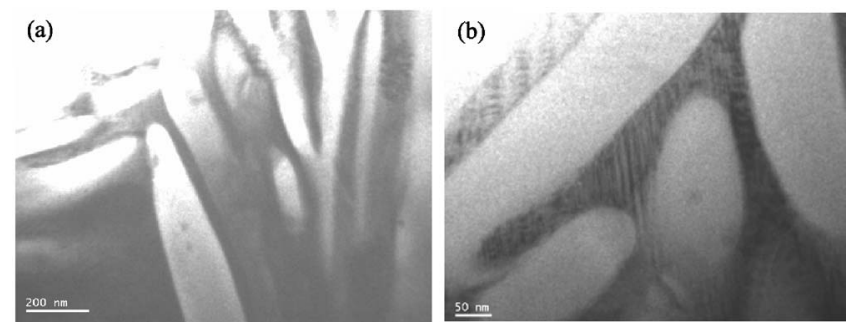

FIG. 3. Transmission electron micrographs revealing the microstructure of the $\left(\mathrm{Sm}_{0.12} \mathrm{Co}_{0.88}\right)_{95} \mathrm{C}_{5}$ alloy melt spun at $40 \mathrm{~m} / \mathrm{s}$ showing (a) dendritic structures and (b) the second phase, $\mathrm{Sm}_{2} \mathrm{C}_{3}$ in the interdendritic region.

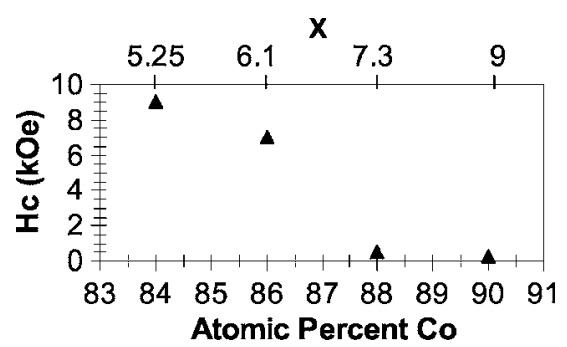

FIG. 4. Relationship between at. $\% \mathrm{Co}$ and intrinsic coercivity for the $\mathrm{SmCo}_{x}$ alloys $-40 \mathrm{~m} / \mathrm{s}$.

$\mathrm{Sm} /$ Co ratio but on the phase formation. The lack of dependence on $\mathrm{Sm} / \mathrm{Co}$ ratio was somewhat surprising, given the strong dependence of coercivity on the $\mathrm{Sm} / \mathrm{Co}$ ratio in $\mathrm{Sm}-$ $\mathrm{Co}-\mathrm{Nb}-\mathrm{C}$ alloys. ${ }^{9}$ Here, a dramatic decrease in coercivity coincided with the formation of Co (Fig. 4). The $\sim 80 \mathrm{~nm}$ fcc Co evidently enables reversal, which reduces the coercivity. Interestingly, the $x=6.1$ and 5.25 alloys had rather high coercivities, especially considering the rather coarse grains which may exceed the single-domain limit for these compounds.

The addition of 3 at. \% $\mathrm{Nb}$ or $\mathrm{C}$ significantly improved the coercivity of the $\mathrm{SmCo}_{x}$ with $x=7.3$ (Fig. 5). Additionally, the energy products were improved to 6-8 MGOe, excellent values for isotropic Sm-Co-based permanent magnets. The improved coercivity is due to the concomitant reduction in grain size. The increase in the $\mathrm{C}$-added alloy is also due to the formation of the grain boundary phase, which effectively isolates the hard magnetic grains from one another. This is also readily evident in the alloy with 5 at. \% C, which had a coercivity of $37 \mathrm{kOe}$. The dramatic increase here is due to the decreased magnetostatic interactions between the well-isolated $\mathrm{SmCo}_{7}$ grains.

\section{CONCLUSIONS}

The binary SmCo melt-spun ribbons can achieve better microstructures and magnetic properties when modified with $\mathrm{Nb}$ and $\mathrm{C}$ additions. The addition of $\mathrm{Nb}$ helps to reduce the size of the (1:7) phase and thus helps to improve coercivity. The addition of $\mathrm{C}$ results in morphological changes in the microstructure which reveals the source of high coercivity, the isolated smooth interfaces. The intergranular region of

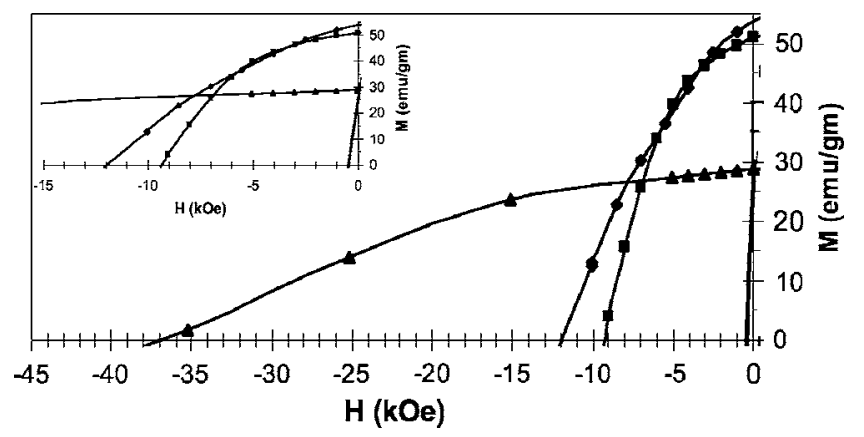

FIG. 5. Demagnetization curves for the $\left(\mathrm{SmCo}_{7.3}\right)_{100-y} T_{y}-40 \mathrm{~m} / \mathrm{s}$ alloys at different $T$ and $y$ values: $T=\mathrm{Nb}$ and $y=3(\boldsymbol{\square}), T=\mathrm{C}$ and $y=3(\bullet)$, and $T$ $=\mathrm{C}$ and $y=5(\boldsymbol{\Lambda})$. The curve $(-)$ is indicating the sample without any additive. The inset shows an expanded view of the region from $0 \mathrm{kOe}$ to $-15 \mathrm{kOe}$. 
the grain boundary contains a different phase that separates the grains and thus lowers the magnetostatic energy resulting in the higher coercivity.

\section{ACKNOWLEDGMENTS}

This project was supported by the National Science Foundation under Grant No. DMR0305354. The authors also benefited greatly from the shared facilities at the University of Nebraska's Materials Research Science and Engineering Center, QSPINS, funded by the National Science Foundation. Support from the Nebraska Research Initiative is also greatly appreciated.
${ }^{1}$ W. Gong and B. M. Ma, J. Appl. Phys. 85, 4657 (1999).

${ }^{2}$ A. Yan, O. Gutfleisch, A. Handstein, T. Gemming, and K.-H. Müller, J. Appl. Phys. 93, 7975 (2003).

${ }^{3}$ A. Yan, A. Bollero, K. H. Müller, and O. Gutfleisch, Appl. Phys. Lett. 80, 1243 (2002).

${ }^{4}$ A. Yan, A. Bollero, K. H. Müller, and O. Gutfleisch, J. Appl. Phys. 91, 8825 (2002).

${ }^{5}$ S. S. Makridis, G. Litsardakis, I. Panagiotopoulos, D. Niarchos, Y. Zhang, and G. C. Hadjipanayis, IEEE Trans. Magn. 38, 2922 (2002).

${ }^{6}$ S. S. Makridis, G. Litsardakis, I. Panagiotopoulos, D. Niarchos, and G. C. Hadjipanayis, J. Appl. Phys. 91, 7899 (2002)

${ }^{7}$ C. H. Chen, S. Kodat, M. H. Walmer, S.-F. Cheng, M. A. Willard, and V. G. Harris, J. Appl. Phys. 93, 7966 (2003).

${ }^{8}$ V. K. Ravindran, MS thesis, University Of Nebraska-Lincoln, 2005.

${ }^{9}$ S. Aich and J. E. Shield, J. Magn. Magn. Mater. 279, 76 (2004). 